\title{
Gupeiite Body in the Siberian Taiga (the Zone of Passage of the Tunguska Meteorite and the Vitim Bollid)
}

\section{Natalya Evgenievna Savva, Pavel Sergeevich Minyuk, Tatiana Vladimirovna Subbotnikova}

Federal State Budgetary Institution North-Eastern Integrated Research Institute Named after N.A. Shilo of the Far Eastern Branch of the Russian Academy of Sciences, Magadan, Russia

Email: nsavva7803@mail.ru, minyuk@neisri.ru

How to cite this paper: Savva, N.E., Minyuk, P.S. and Subbotnikova, T.V. (2022) Gupeiite Body in the Siberian Taiga (the Zone of Passage of the Tunguska Meteorite and the Vitim Bollid). Natural Resources, 13, 53-64.

https://doi.org/10.4236/nr.2022.132004

Received: November 9, 2021

Accepted: February 25, 2022

Published: February 28, 2022

\section{Copyright $\odot 2022$ by author(s) and} Scientific Research Publishing Inc. This work is licensed under the Creative Commons Attribution International License (CC BY 4.0).

http://creativecommons.org/licenses/by/4.0/

\begin{abstract}
Many years have passed since the two cosmic bodies of the Tunguska meteorite and the Vitim bollid fell to Earth, but so far the substance of these bodies has not been found on Earth. Therefore, each metal body found on the territory of their passage is of particular interest. The body of iron silicide weighing $12 \mathrm{~kg}$ was studied, which was accidentally discovered by a hunter of the village of Kyker in the Siberian taiga on the right bank of the Nercha River, Tungokochensky district, Trans-Baikal Territory. Coordinates of the place of discovery are: $53^{\circ} 19^{\prime} \mathrm{N}$ lat, $116^{\circ} 19^{\prime} \mathrm{E}$ long. The territory is located in the zone of the passage of the Tunguska meteorite and the Vitim bollid, $25 \mathrm{~km}$ from the hunting village of Green Lake. The body is named "Ilekta" after the nearest stream flowing into the Nercha River. The composition and magnetic properties of the exotic find have been determined. It is established that its main mass is composed of iron silicide, gupesiite Fe3Si (zussite?) and contains inclusions of needle-like rhabdite. On the surface, the body is covered with a melting crust, with signs of boiling, a bubbly structure and a film of clay minerals of terrestrial origin. In the molten porous crust, eutectic-schreibersite-gupeiite is observed, and rare titanium carbide crystals are also noted. The magnetic susceptibility of the samples is not uniform (286.6 $461.810-6 \mathrm{E}-06 \mathrm{~m}^{3} / \mathrm{kg}$ ). It is assumed that a drop of melt separated from the flying space body, and experienced overheating and boiling of the surface layer in the dense layers of the atmosphere.
\end{abstract}

\section{Keywords}

Gupeiite, Melting Crust, Cosmos, Tunguska Meteorite 


\section{Introduction}

Iron silicides are natural compounds of iron and silicon, represented by a small group of minerals, which currently includes 12 mineral species. The most famous minerals are iron silicides: gupeiite $\left(\mathrm{Fe}_{3} \mathrm{Si}\right)$, hapkeite $\left(\mathrm{Fe}_{2} \mathrm{Si}\right)$, linjiite $\left(\mathrm{FeSi}_{2}\right)$, luobusaite $\left(\mathrm{Fe}_{0.84} \mathrm{Si}_{2}\right)$, nakite $(\mathrm{FeSi})$, susite $(\mathrm{Fe}, \mathrm{Ni})_{3} \mathrm{Si}$ and zangboite $\left(\mathrm{TiFeSi}_{2}\right)$. Gupeiite is extremely rare in nature and has been little characterized in publications, as well as its analogue zussite [1]-[6]. According to the mineralogical website https://www.mindat.org/, findings of various iron and silicon compounds are known: in iron-stone meteorites (zussite, linzhiite, nagchuit, perriite, hapkeite) and cometary matter (brownliite), in oceanic sediments, iron-manganese nodules (zussite, jifengite), fulgurites (nagchuit, tsangpoite), in modern and ancient placers (gupeyite, zussite, linzhiite, mavlyanovite, nagchuit, jifengite).

Gupeiite (Fe3Si; IMA 1983-087) was described and named after the Yansshan meteorite of Hebei Province (China), where it was first found in 1984 [1]. The mineral is formed in an environment devoid of oxygen, perhaps even in space. Artificial production of $12 \mathrm{~kg}$ gupeyite mass in terrestrial conditions is impossible. This is due to the fact that gupeyite is obtained in a high vacuum of $10^{-7} \mathrm{~Pa}$. When iron atoms interact with the silicon surface, super-thin films are formed, growing at a rate of $0.16 \mathrm{~nm} / \mathrm{min}$ [7] [8]. In the reference data, gupeyite is classified as a rare mineral of cosmic origin.

The aim of the study was to establish the features of the composition and magnetic properties of a metal body found in the Siberian taiga, in the zone of passage of large cosmic bodies, and an attempt to determine its origin.

\section{The History of the Find}

The specimen, named "Ilekta", was accidentally discovered by a hunter from the village of Kyker, Tungokochensky district, Trans-Baikal Territory on the right bank of the Nercha River in its middle course. Coordinates of the location of the find: $53^{\circ} 19^{\prime} \mathrm{N}$ lat, $116^{\circ} 19^{\prime} \mathrm{E}$ long. $25 \mathrm{~km}$ below the mouth of the Nerchugan creek, in the vicinity of the mouth of the Ilekta creek of the right tributary of the Nercha River in the zone of the passage of the Tunguska meteorite and the Vitim bollid (Figure 1).

The sample was found by local residents on the slightly swampy surface of the floodplain terrace (Figure 2), in a depression of $0.3-0.5 \mathrm{~m}$ (presumably these are preserved traces of a funnel). The hunter Nikolay Dunaev immediately drew attention to the rounded shape of the stone, its pitted surface, large weight (12 kg.), melting, high magnetism and metallicity of the main mass on a fresh chip (Figure 3).

A similar sample in this taiga region was found for the first time, although geologists mapped the area at a scale of 1:200,000 and partially at 1:50,000, but no such formations were found. There is no information about anything like this in the archival materials. 


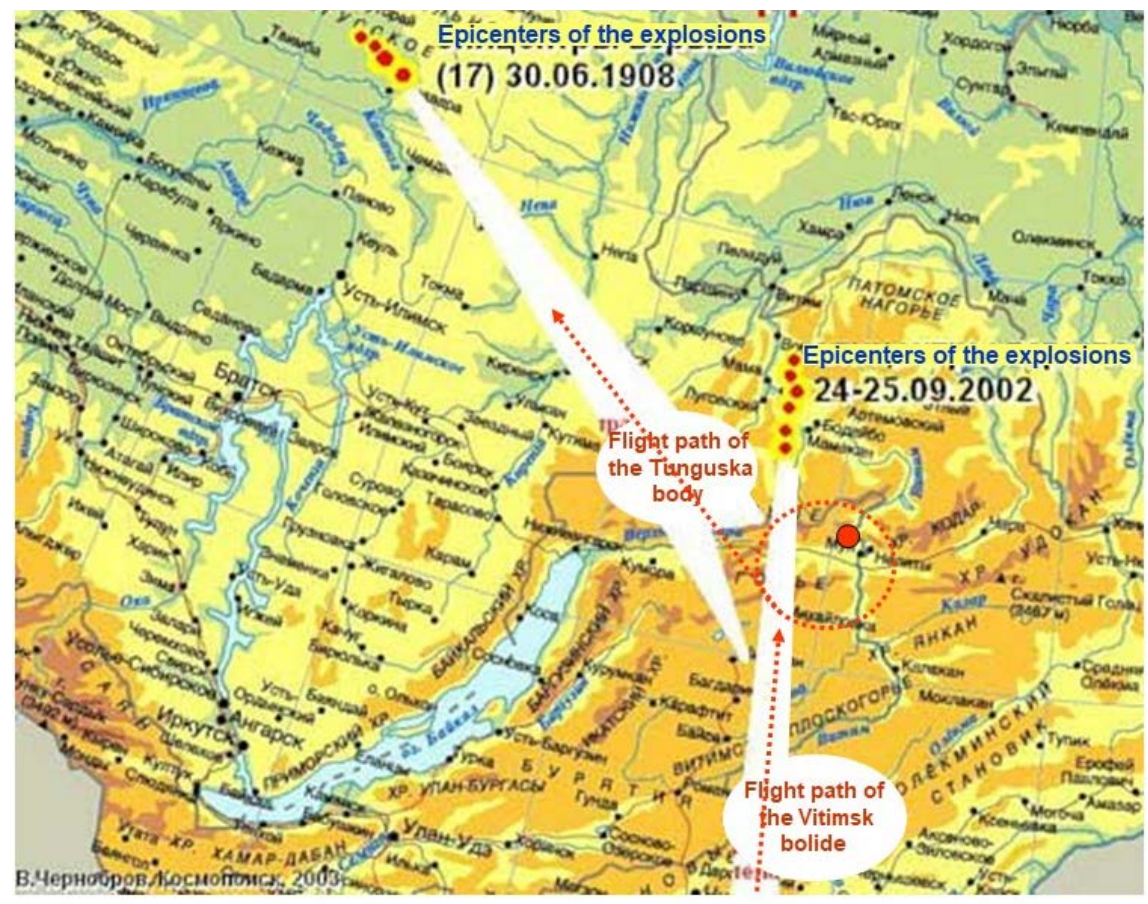

$80 \quad 160 \mathrm{Km}$

(a)

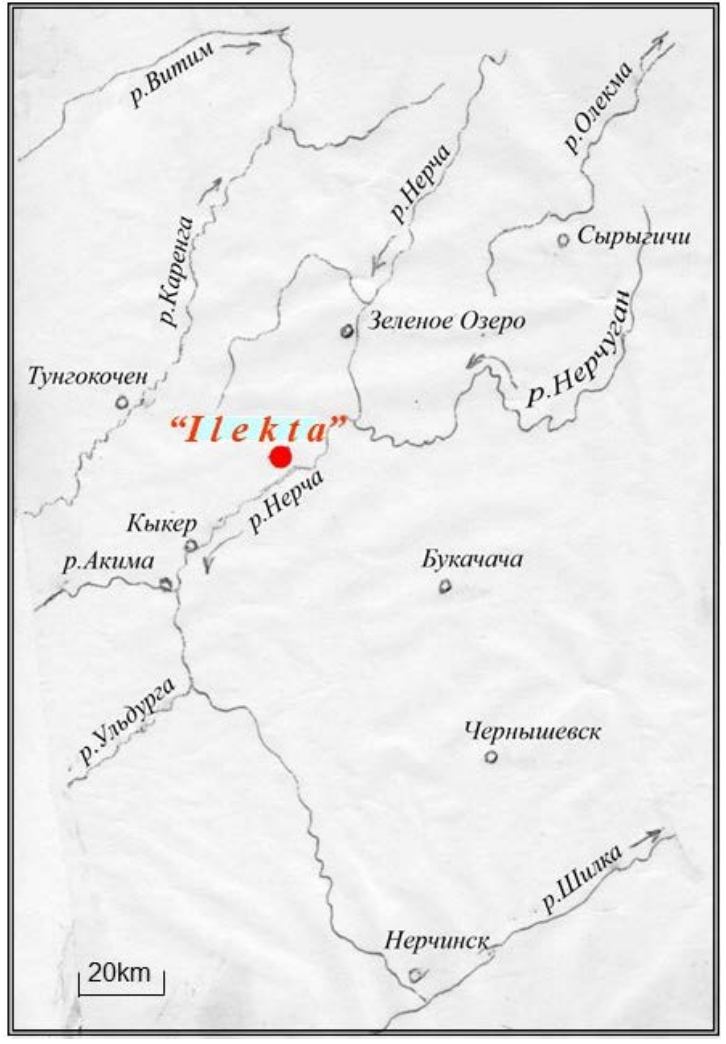

(b)

Figure 1. The place of the fall of the body of gupate, named "Ilekta": (a) the trajectory of the passage of the Tunguska meteorite and the Vitim bolide (the dotted line shows the place of the discovery of the body of "Ilekta"); (b) the details of the place of the find. 


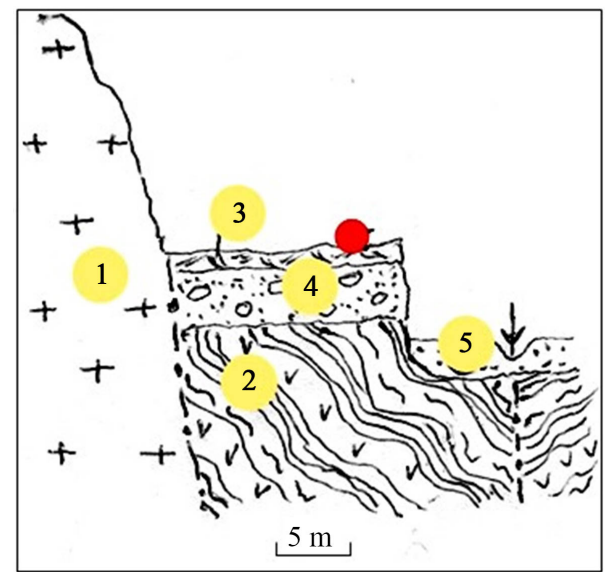

Figure 2. The position of the "Ilekta" in the above-floodplain terrace, the arrow shows the bed of the Ilekta stream (sketch by N. P. Berzin). 1 granite-gneiss complex of the lower Proterozoic of the Chersky ridge; 2 volcanogenic-terrigenous complex; upper Mesozoic of the Nerchinsk depression; 3 slightly swampy surface of the above-floodplain terraces; 4 alluvium of above-floodplain terraces; 5 alluvium of the Nercha River floodplain; the place of finding the sample "Ilekta".

\section{The Appearance of the Object}

The body has a metallic luster, a rounded and oxidized surface. It is a small boulder measuring $15 \mathrm{~cm}$ long, $9 \mathrm{~cm}$ high (Figure 3, Figure 4), variable width from $8 \mathrm{~cm}$ to 1 wedge-shaped at one end (Figure 4(a), Figure 4(b)). There is a melting crust on the surface and signs of boiling (Figure 3, Figure 4(c)). The melting crust is clearly visible on the chip (Figure 4(a), Figure 4(b)).

This important to note that the brown ferruginous-clay crust $1-3 \mathrm{~mm}$ thick on the surface of the sample consists of Fe oxides and may contain substances of Terrestrial origin, since the body was in a funnel and came into contact with river water, silt and air oxygen. The thickness of the oxidation crust indicates that the body has lain in the funnel for a long time, since its bulk, presumably consisting of gupeiite, is resistant to oxidation and in the central part is represented by a dense substance without voids. Plastic deformations, presumably obtained in the hot state (Figure 4(d)), and brittle ones during cooling (Figure 4(e)), established during the sample cutting, are clearly visible on the cut of the sample.

According to hunters in Bratsk, Irkutsk region, for 2.5 thousand $\mathrm{km}$, a ferrosilicon of a different composition is produced at a metallurgical plant, which does not correspond to the composition of the found sample. This material could not get into the Siberian taiga, where there is not even a regular highway. The nearest settlements to the site of the sample are the village of Kyker and the village of Zelenoe Ozero. In the village of Kyker from the day of its foundation (1668) to the present time there is no industry at all, especially metallurgical. In the village of Zelenoe Lake, there are 60 people of hereditary hunters engaged only in hunting. The population of these settlements knows nothing about such formations. 


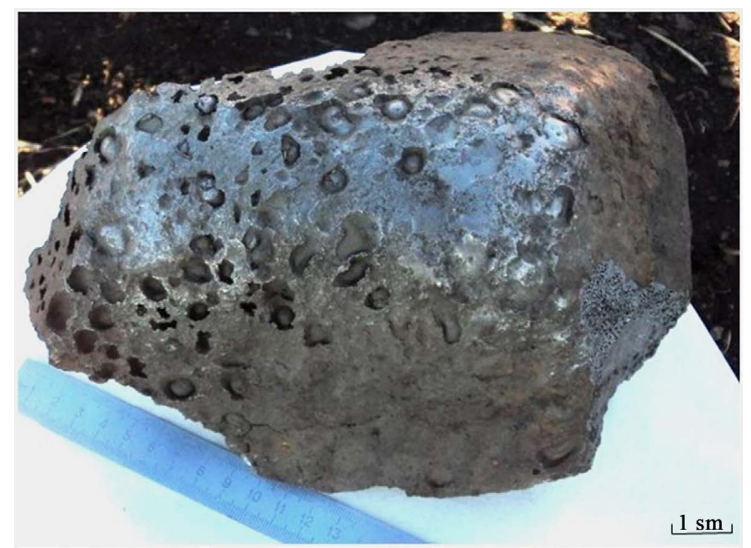

Figure 3. General view of the "Ilekta" find (photo by G.P. Berzin).
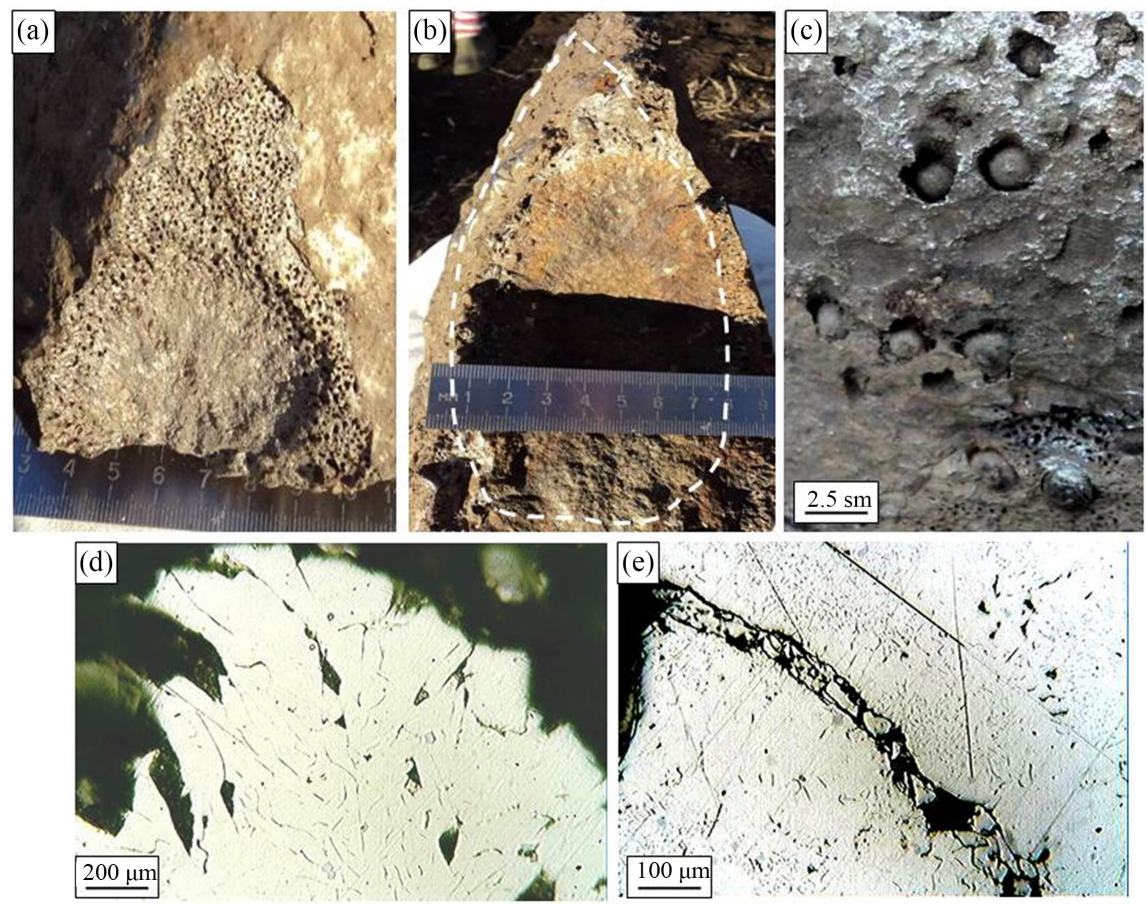

Figure 4. Features of the morphology of the gupeite body: (a)-(b) wedge-shaped cross-section of the "Ilekta" sample on the chip (photo of one of the hunters, Gennady Porfirievich.Berzin); (c) bubble surface; plastic (d) and brittle (e) deformations clearly visible on the slice.

\section{Research Methods}

Preliminary diagnostics was performed at IGiM SB RAS, Novosibirsk on the JSM-6510LV SEM (JEOL Ltd) device with a microanalysis system (Oxford Instruments). N.P. Berzin sent three fragments of the object "Ilekta" with a size of $1.5 \times 2.0 \times 5.0 \mathrm{~cm}$ to the authors of this article for research. Three polished preparations were made from them. The optical properties of the minerals composing the sample were studied using an AXIOPLAN Imagin microscope [9]. The composition was determined by T.V. Subbotnikova with a micro-X-ray spectral (MRS) analyzer on a CAMEBAX device with the prefix INCA (Oxford), 
Magadan. The CAMEBAX device also took photographs of the sample fragments in characteristic X-rays. Structural etching was carried out with concentrated $\mathrm{HCl}$. Measurements of magnetic susceptibility (k, MV) at room and high temperatures $(\mathrm{k}-\mathrm{T})$ were carried out on a multifunctional MFK1-FA kappameter with a CS-3 thermal insert (AGICO Ltd.). The heating and cooling rate was about $12^{\circ} \mathrm{C}-13^{\circ} \mathrm{C}$ per minute, the maximum heating temperature was $700^{\circ} \mathrm{C}$, the heating was carried out in an argon medium. Hysteresis parameters, including residual saturation magnetization (Jrs), saturation magnetization (Js), inductive magnetization (Ji), coercive force $(\mathrm{Hc})$, residual coercive force $(\mathrm{Hcr})$, were measured on an automatic coercitimeter J-meter. The maximum field induction was $500 \mathrm{mt}$. Thermomagnetic analysis (Js-T) was performed on magnetic scales in an induction field of $500 \mathrm{mt}$.

\section{Results of the Composition Study}

Initially, when studying an exotic find, a scan of its surface was performed. It was previously known that the chemical composition of the sample corresponds to iron silicide ( $\mathrm{Fe} 3 \mathrm{Si}$ ) and is covered with a film of clay-mica minerals with an admixture of Fe hydroxides (Table 1). In the same place, in the surface layer of the sample, the methods ME-ICP and ME-OG6 were established: Ni - 0.11; Co 0.03 ; $\mathrm{Ti}-0.49$; $\mathrm{Mn}-1.03$; P - $2.6 \mathrm{wt} \%$.

Table 1. The composition of mineral phases on the surface of the sample "Ilekta" according to the data of microrentgenospectral analysis, wt $\%$.

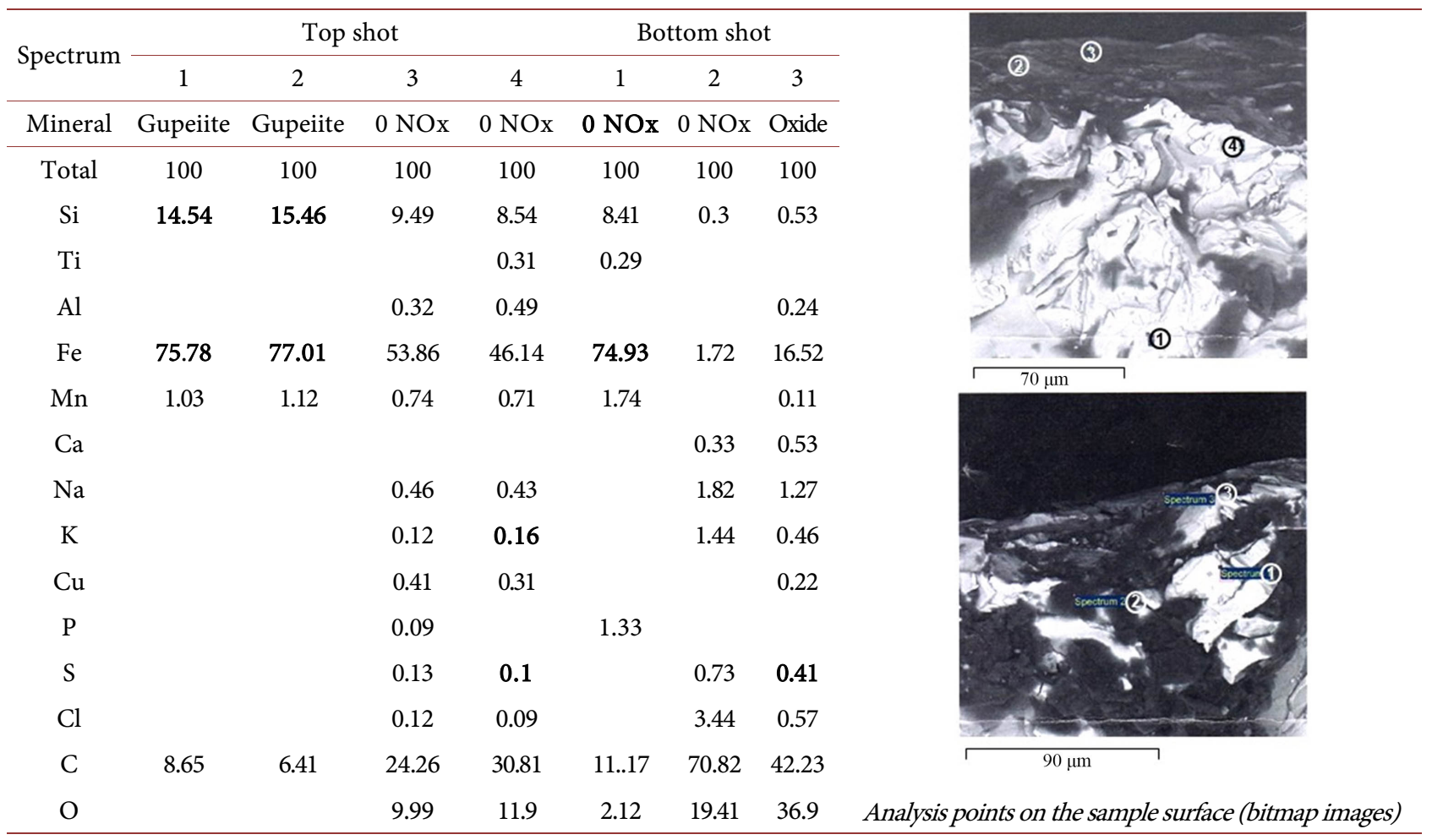

JSM-6510LV SEM (JEOL Ltd.) with microanalysis system (Oxford Instruments), analyst Karmanov N.S. Novosibirsk, IGM SB RAS. 
The main matrix consists of gupeiite $\mathrm{Fe} 3 \mathrm{Si}$, a rare iron silicide (Figure 5). Trapezoidal crystalline inclusions in the melting crust are represented by titanium carbide (up to $68.5 \mathrm{wt} \% \mathrm{Ti}$ ), manganese iron phosphide, corresponding in composition to manganese schreibersite, is also present in the eutectic melt, and naturally located inclusions of needle-like crystals of rhabdite are noted in the matrix of iron silicide (Figures 5(a)-(c)). Figure 6 shows the distribution of Fe, $\mathrm{P}, \mathrm{Si}, \mathrm{Mn}$ in characteristic X-rays.

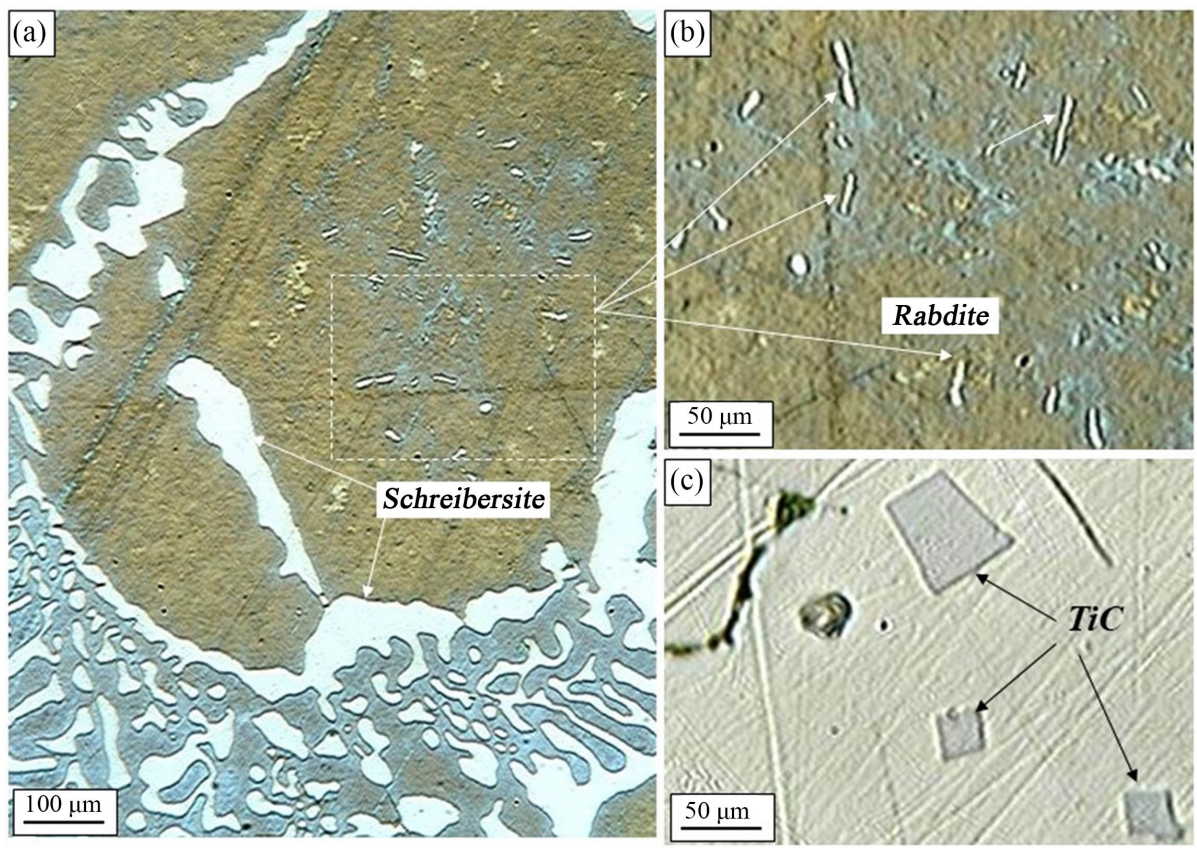

Figure 5. Mineral phases of "Ilecta" in reflected light: (a)-(b) eutectic decomposition of gupeiite with schreibersite and needle crystals of rhabdite in gupeiite (structural etching of $\mathrm{HCl}$ ); (c) crystals of Ti carbide in gupeiite.
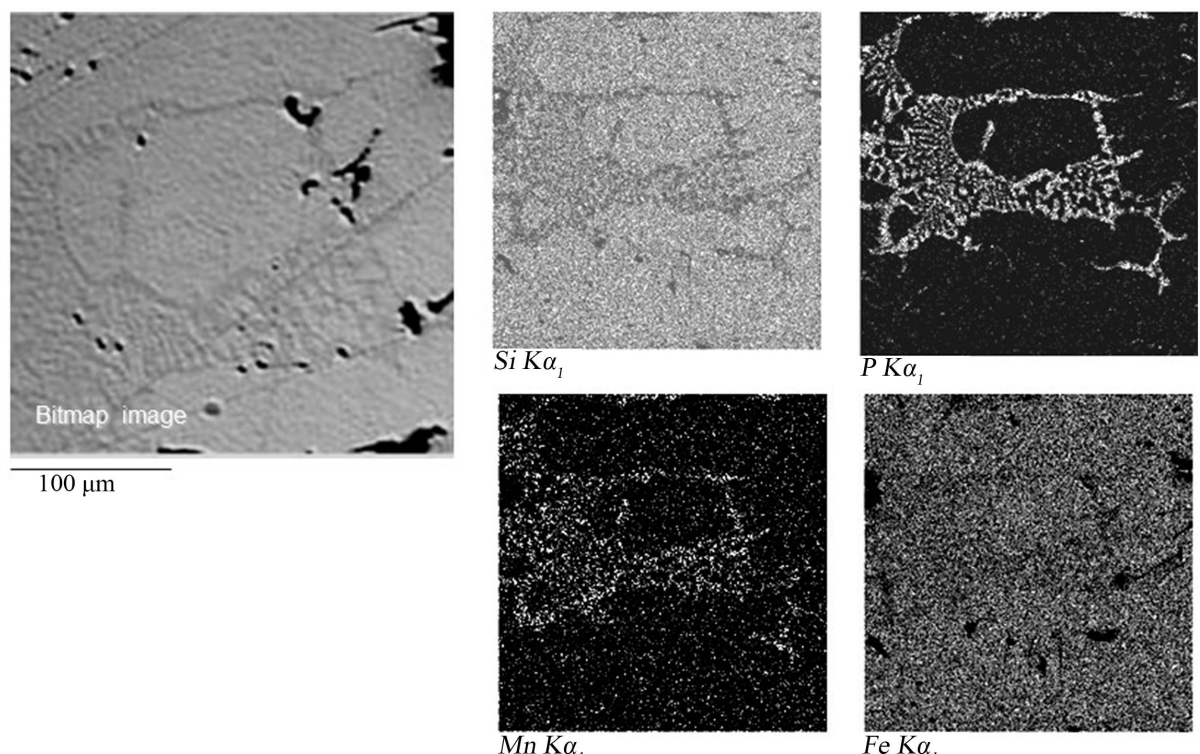

$\mathrm{Fe} K \alpha_{1}$

Figure 6. Distribution of mineral phases in characteristic X-ray radiation. 
The composition of the mineral phases of "Ilekta" is shown in Table 2 and confirmed by raster scanning in characteristic X-rays (Figure 6). The MRS method revealed several mineral phases with different optical properties (Table 2).

\section{Magnetic Properties of the "Ilecta" Sample}

The magnetic susceptibility of the samples is not uniform (286.6 - $461.810-6 \mathrm{E}-06$ $\mathrm{m}^{3} / \mathrm{kg}$ ). A higher magnetic susceptibility was noted for model 1 , where it is 1.5 times higher in magnitude than the MV of other samples (Table 3)

Table 2. Results of MRC analysis of various phases of the sample, wt\%.

\begin{tabular}{|c|c|c|c|c|c|c|}
\hline $\mathrm{Si}$ & $\mathrm{P}$ & $\mathrm{Ti}$ & $\mathrm{Cr}$ & $\mathrm{Mn}$ & $\mathrm{Fe}$ & Итог \\
\hline \multicolumn{7}{|c|}{ Schreibersite $(\mathrm{Fe} . \mathrm{Mn})_{3} P$ in the eutectic of the melting crust } \\
\hline 6.62 & 15.27 & 1.79 & 0.51 & 5.24 & 73.53 & 102.96 \\
\hline 7.53 & 13.79 & 0.63 & 0.41 & 5.28 & 74.83 & 102.47 \\
\hline 6.99 & 14.60 & 0.72 & 0.40 & 5.15 & 75.38 & 103.24 \\
\hline 7.29 & 14.23 & 0.58 & 0.36 & 5.00 & 75.65 & 103.11 \\
\hline \multicolumn{7}{|c|}{ Gupeiite $\mathrm{Fe}_{3} \mathrm{Si}$} \\
\hline \multicolumn{7}{|c|}{ In the melting crust } \\
\hline 15.35 & 0.42 & & & 1.09 & 86.57 & 103.43 \\
\hline 15.54 & & & & 1.23 & 86.87 & 103.63 \\
\hline 15.54 & & & & 1.15 & 85.73 & 102.42 \\
\hline 14.97 & 0.32 & & & 1.13 & 82.50 & 98.91 \\
\hline 14.68 & 0.32 & & & 1.17 & 81.60 & 97.77 \\
\hline 14.63 & 0.30 & & & 1.06 & 83.78 & 99.76 \\
\hline 15.54 & & & & 1.15 & 85.73 & 102.42 \\
\hline \multicolumn{7}{|c|}{ In the bulk of the body } \\
\hline 15.38 & & 1.17 & & & 85.48 & 102.03 \\
\hline 15.40 & & 1.25 & & & 85.60 & 102.24 \\
\hline 15.49 & & 1.19 & & & 85.33 & 102.01 \\
\hline 15.30 & & 1.13 & & & 85.52 & 101.96 \\
\hline \multicolumn{7}{|c|}{ Titanium carbide?TiC } \\
\hline & & 68.50 & & & 2.70 & 71.20 \\
\hline 0.26 & 0.56 & 65.90 & 1.86 & 0.17 & 3.82 & 72.58 \\
\hline 30.25 & 4.35 & 47.48 & 0.80 & & & 90.44 \\
\hline
\end{tabular}

Note: CAMEBAX with microanalysis system (Oxford Instruments) analyst T.V. Subbotnikova, SVKNII FEB RAS, Magadan (carbon deposition was performed, therefore carbon is excluded from the analysis).

Table 3. Magnetic properties of the "Ilecta" sample.

\begin{tabular}{ccc}
\hline Fragments of the sample & Bec, $g$ & Magnetic properties, $\mathrm{m}^{3} / \mathrm{kg}$ \\
\hline 1 the inner part of the fragment & 7.40 & $461.8 \mathrm{E}-06$ \\
2 middle part & 2.79 & $286.6 \mathrm{E}-06$ \\
3 middle part & 2.73 & $294.1 \mathrm{E}-06$ \\
4 the outer part of the fragment & 25.28 & $300.1 \mathrm{E}-06$ \\
\hline
\end{tabular}


On the thermocappametry curves $(\mathrm{k}-\mathrm{T})$ obtained during the heating of the powder in an argon medium, the main decrease in magnetic susceptibility occurs at a temperature of about $560{ }^{\circ} \mathrm{C}$ (Figure 7). This temperature is more clearly expressed on the cooling curves, which are located above the heating curves. This temperature apparently corresponds to the Curie point $\mathrm{Fe} 3 \mathrm{Si}$, which is $566.8^{\circ} \mathrm{C}$ $576.85^{\circ} \mathrm{C}$ [7] [8]. The heating curves show a slight inflection at a temperature of $\sim 470^{\circ} \mathrm{C}$, possibly associated with iron phosphide (schreibersite). Nickel-free schreibersite of the Kolyma fulgurite has a Curie point of $\sim 440^{\circ} \mathrm{C}[10]$
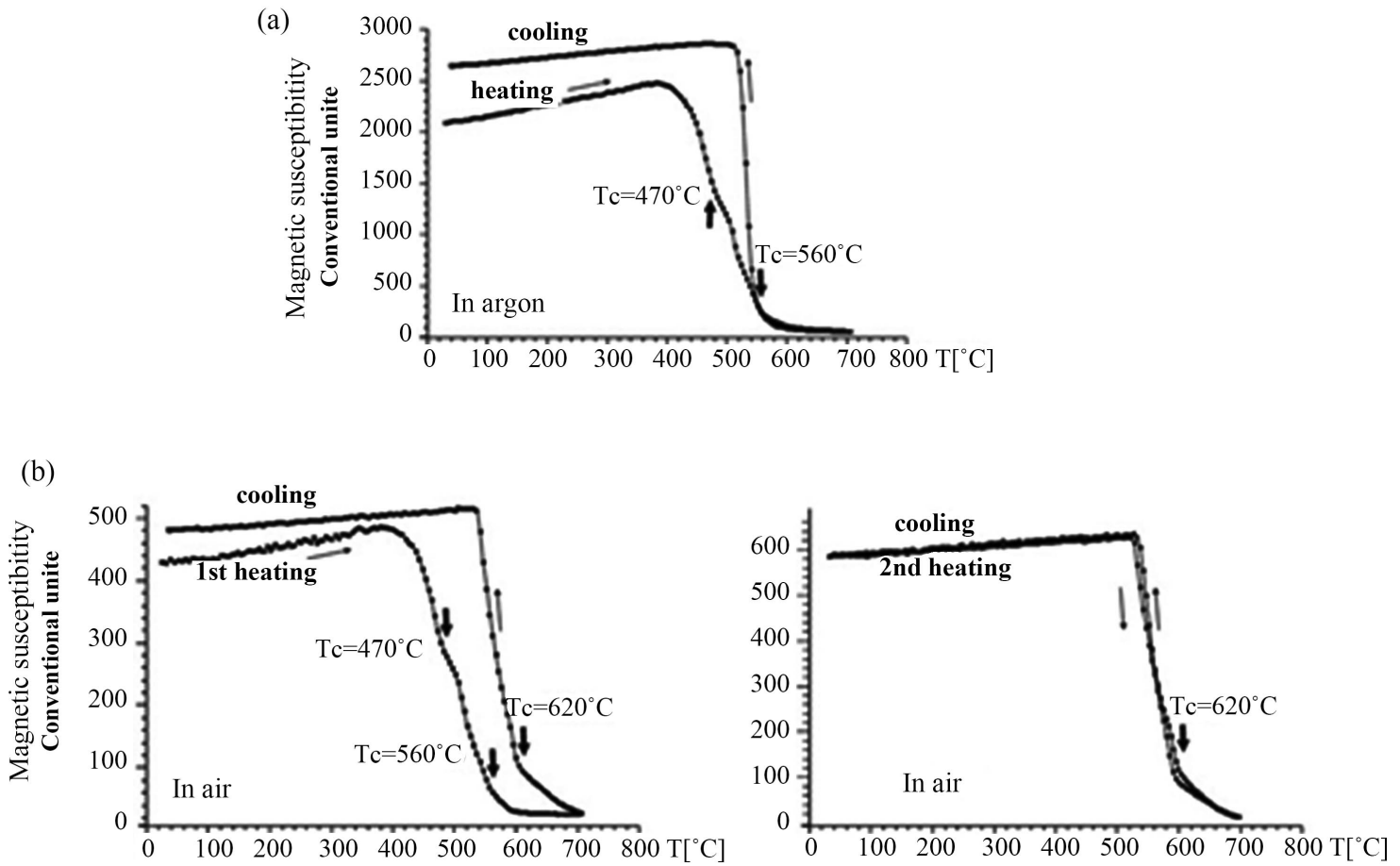

(c)
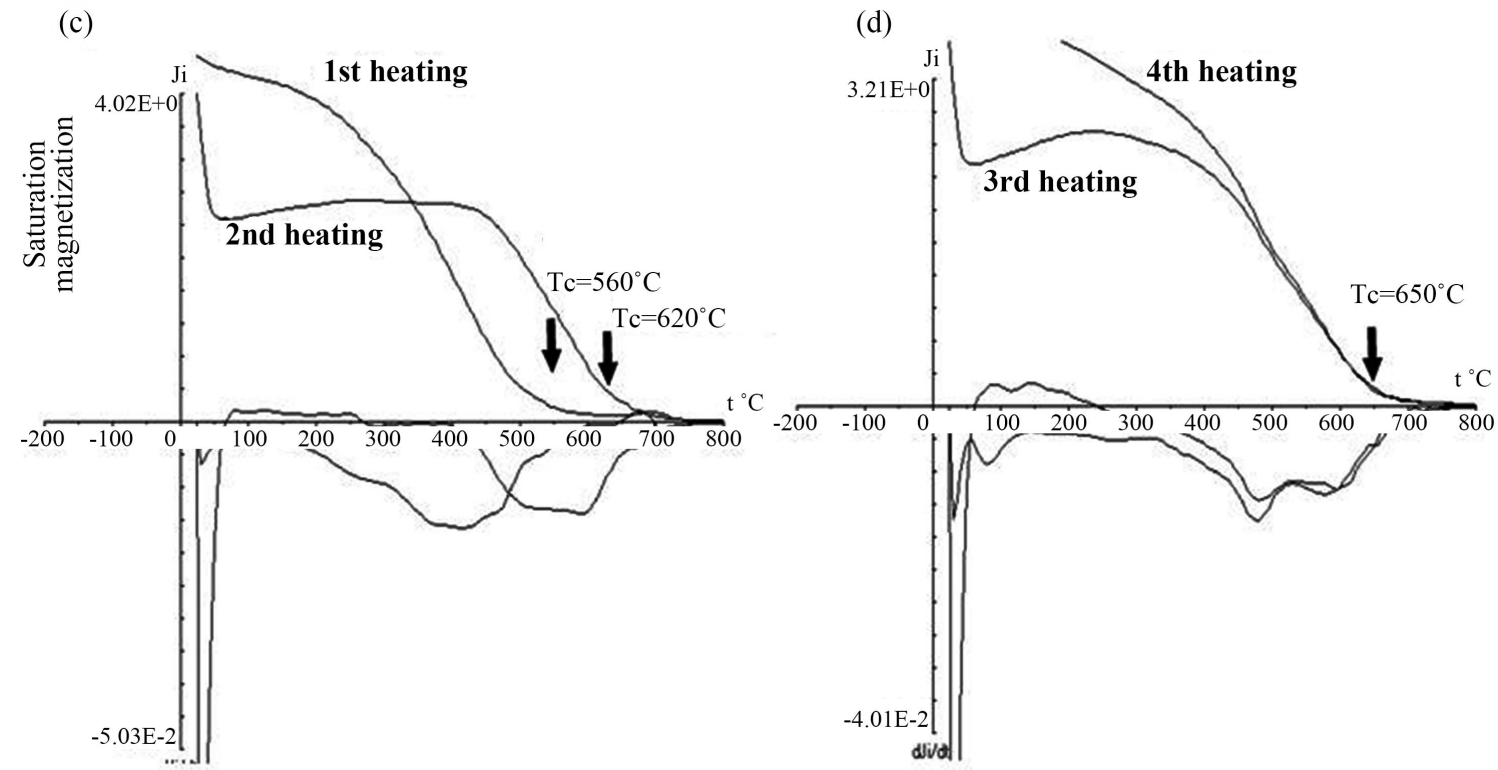

Figure 7. Magnetic properties of the Ilekta sample: (a)-(b) thermocappametry curves in argon (a) and air (b): (c) dependence of saturation magnetization on temperature (the lower part of the graphs are differential curves). 
On the k-T heating curves obtained in argon and air (Figure 7(a), Figure 7(b)), the same mineral phases are isolated at the Curie points, but strong oxidation occurs. The Curie point of the main phase shifts to a temperature of $620^{\circ} \mathrm{C}$, which is reflected in the cooling curve (Figure $7(\mathrm{c})$ ). In the process of heating and cooling of the second cycle of mineral transformations does not occur, the heating and cooling curves are repeatable.

Thermomagnetic analysis of samples performed on magnetic scales shows similar results in many respects. On the heating curves of saturation magnetization from temperature (Js-T), an inflection in the temperature range of $560^{\circ} \mathrm{C}$ is clearly distinguished. The experiment was performed in an air environment. During the second heating, the temperature of the main magnetization decay shifts to $620^{\circ} \mathrm{C}$ (Figure $7(\mathrm{~b})$ ), and at the $3 \mathrm{rd}$ and 4 th heats to $650^{\circ} \mathrm{C}$ and higher (Figure 7(b)).

The magnetic hysteresis parameters obtained before and after heating of the sample show that the structure of the magnetic substance is multi-domain, the ratio Jrs/Js $=0.02, \mathrm{Bcr} / \mathrm{Bc}=8$ (Table 4 , Figure $7(\mathrm{c})$, Figure $7(\mathrm{~d})$ ). After warming up, the values of saturation magnetization and residual saturation magnetization decrease, while the coercive force and residual coercive force increase (Table 4). Newly formed minerals are more magnetically rigid.

The Curie point of the mineral $\left(650^{\circ} \mathrm{C}\right)$ is close to hematite, but its magnetic parameters differ from hematite. Firstly, if the all oxidized mineral corresponded to hematite, then its saturation magnetization would be hundreds of times lower than that of an unheated sample. The values of Bcr and Bc should also be higher. According to [11], the average values of $\mathrm{Bcr}$ and $\mathrm{Bc}$ for hematite are $318 \mathrm{Mt}$ and $268 \mathrm{Mt}$, respectively.

\section{Discussion of the Results}

Of the study showed that the metal body of the Electa found by hunters in the Siberian taiga mainly consists of a compound of iron and silicon and corresponds in composition to gupeite $\left(\mathrm{Fe}_{3} \mathrm{Si}\right)$, an exotic mineral for the Earth. Gupeiite contains inclusions of needle-like rhabdite. In the melting crust, the eutectic of schreibersite-gupeite is noted. Plastic deformations (Figure $4(\mathrm{~d})$ ) indicate that the body fell to the Earth's surface in a molten (hot) state. This could happen during the passage of dense layers of the atmosphere. The body of the Elect also has brittle deformations (Figure 4(e)) formed after its cooling. Its inhomogeneous magnetic susceptibility $\left(\mathrm{m}^{3} / \mathrm{kg}\right)$ is noted: $286.6,461.8 \mathrm{E}-06$, higher in the inner part and lower in the surface layer.

Table 4. Magnetic hysteresis data of the Ilecta sample.

\begin{tabular}{ccccccc}
\hline Sample & $\mathrm{Jr}, \mathrm{A} \mathrm{m}^{2} / \mathrm{kg}$ & $\mathrm{Js}, \mathrm{A} \mathrm{A} \mathrm{m}^{2} / \mathrm{kg}$ & $\mathrm{Bcr}, \mathrm{mTl}$ & $\mathrm{Bc}, \mathrm{mTl}$ & $\mathrm{Jr} / \mathrm{Ji}$ & $\mathrm{Bcr} / \mathrm{Bc}$ \\
\hline Before heating & $1.86 \mathrm{E}+00$ & $7.99 \mathrm{E}+01$ & 9.6 & 1.2 & $2.33 \mathrm{E}-02$ & 8 \\
After heating & $8.23 \mathrm{E}-01$ & $2.80 \mathrm{E}+01$ & 15.3 & 15.3 & $2.94 \mathrm{E}-02$ & 1 \\
\hline
\end{tabular}


Presumably, the body came to Earth from space, since previously it was noted that a very high vacuum was needed $10^{-7} \mathrm{~Pa}$, even for obtaining the thinnest films of gupeite [8]. Probably the gupeiite body, which has the shape of a large drop, could have separated from the cosmic body and this "drop" melted with the boiling of the surface layer in the dense layers of the atmosphere, partially losing its magnetic properties upon impact with the earth.

The authors of the article are inclined to the cosmic or technogenic-cosmic origin of the found gupeiite body. It is possible that the place of its fall was at another point in the basin of the river Vitim and subsequently it was brought to the river terrace by flood waters.

The main part of the body of the "Ilekt" is kept by Berzin Gennady Parfentievich. Address: 672522, Zabaikalsky Krai, Chita district, village. Ingoda, Linnaya str., 12 Tel. 8-302-2-37-32-22 and 8-924-508-22-79.

The authors express their gratitude to Berzin Gennady Parfentievich for the detailed information provided for the study of samples.

\section{Conflicts of Interest}

The authors declare no conflicts of interest regarding the publication of this paper.

\section{References}

[1] Yu, Z.X. (1984) Two New Minerals Gupeiite and Xifengite in Cosmic Dusts from Yanshan. Acta Petrologica Mineralogica et Analytica, 3, 231-238. (in Chinese with English Abstract)

[2] Novogorodova, M.I., Yusupov, R.G., Dmitrieva, M.T., Tsepin, A.I., Sivtsov, A.V., Gorshkov, A.I., Korovushkin, V.V. and Yakubovskaya, N.Yu. (1983) The First Find of Zussite on Earth. Reports of the Academy of Sciences USSR (RAS USSR), 271, 1480-1483.

[3] Keil, K., Berkley, J.L. and Fuchs, L.H. (1982) Suessite, Fe3Si: A New Mineral in the North Haig Ureilite. American Mineralogist, 67, 126-131.

[4] Jenniskens, P., et al. (2009) The Impact and Recovery of Asteroid 2008 TC3. Nature, 458, 485-488.

[5] Shi, N., Bai, W., Li, G., Xiong, M., Yang, J., Ma, Z. and Rong, H. (2012) Naquite, Fe$\mathrm{Si}$, a New Mineral Species from Luobusha, Tibet, Western China. Acta Geologica Sinica (English Edition), 86 533-538. https://doi.org/10.1111/j.1755-6724.2012.00682.x

[6] Nabiei, F., Badro, J., Dennenwaldt, T., Oveisi, E., Cantoni, M., Hébert, C., El Goresy, A., Barrat, J.-A. and Gillet, P. (2018) A Large Planetary Body Inferred from Diamond Inclusions in a Ureilite Meteorite. Nature Communications, 9, Article Number: 1327. https://doi.org/10.1038/s41467-018-03808-6

[7] Tarasov, I.A., Popov, Z.I., Varnakov, S.N., Molokeev, M.S., Fedorov, A.S., Yakovlev, I.A., Fedorov, D.A. and Ovchinnikov, S.G. (2014) Optical Properties of the Epitaxial Film of Iron Silicide $\mathrm{Fe}_{3} \mathrm{Si} / \mathrm{Si}$ (111). JETP Letters, 99, 651-655. https://doi.org/10.1134/S0021364014100105

[8] Ovchinnikov, S.G., Varnakov, S.N., Lyashenko, S.A., Tarasov, I.A., Yakovlev, I.A., Popov, E.A., Zharkov, S.M., Velikanov, D.A., Tarasov, A.S., Zhandun, V.S. and 
Zamkova, N.G. (2016) Ferromagnetic Metal Nanostructures/Semiconductor Based on Iron Silicides. Physics of the Solid State, 58, 2195-2199.

https://doi.org/10.1134/S1063783416110299

[9] Savva, N.E., Minyuk, P.S. and Subbotnikova, T.V. (2019) Exotic Find of Iron Silicid in the Zone of Flyby Tunguska Meteorite and Vitim Space Bolide. X International Scientific Conference: "Scientific Achievements of the Third Millennium", New York, 30 September 2019, 56-62.

[10] Plyashkevich, A.A., Minyuk, P.S., Subbotnikova, T.V. and Alshevsky, A.V. (2016) Newly Formed Minerals of the Fe-P-S System in Kolymsky Fulgurite. Doklady Earth Sciences, 467, 380-383. https://doi.org/10.1134/S1028334X16040139

[11] Peters, C. and Dekkers, M.J. (2003) Selected Room Temperature Magnetic Parameters as a Function of Mineralogy, Concentration and Grain Size. Physics and Chemistry of the Earth, 28, 659-667. https://doi.org/10.1016/S1474-7065(03)00120-7 